Research Article

\title{
Application of PS-INSAR Technique on Health Diagnosis of the Deformable Body on Front Slope beside Mountain Tunnel Portal
}

\author{
Jiaxin Jia $(1)$ \\ Survey and Design Company of Sichuan Road \& Bridge (Group) Co.,Ltd., Chengdu, China \\ Correspondence should be addressed to Jiaxin Jia; 157432187@qq.com
}

Received 18 September 2020; Revised 10 October 2020; Accepted 4 November 2020; Published 29 November 2020

Academic Editor: Zheng-zheng Wang

Copyright (C) 2020 Jiaxin Jia. This is an open access article distributed under the Creative Commons Attribution License, which permits unrestricted use, distribution, and reproduction in any medium, provided the original work is properly cited.

\begin{abstract}
When tunnel construction develops to surrounding mountainous areas, tunnel portal presents the topographic characteristics of "high, steep, and slant" and geological characteristics of kinds of hugely thick colluvial or residual slope, and the health condition of the deformable body on front slope beside tunnel portal has a great influence on tunnel construction and operation. Tunnel portal has suffered from many disasters, and it is urgent to study and solve the engineering problem on how to diagnose the health condition of front slope beside tunnel portal quickly and accurately. Based on the tunnel of Jianquan village, this paper uses PSINSAR technique for the first time to analyze and diagnose the health condition of the deformable body on front slope beside mountain tunnel portal at the construction stage and operation stage, so as to provide early warnings to unstable deformable body at tunnel portal and provide strong bases for the treatment of unstable deformable body. Therefore, PS-INSAR technique promotes the health monitoring method for deformable body on front slope beside mountain tunnel portal to a higher level.
\end{abstract}

\section{Introduction}

Geological problems of tunnel portal primarily include weak foundation of tunnel portal, severe bias of tunnel portal, hugely thick overburden of tunnel portal, and instability of front slope beside tunnel portal [1]. Early detection and early treatment are basic principles for the treatment of surface deformation and even landslide on front slope beside mountain tunnel portal [2]. There are two main types of health monitoring method for deformable body on front slope beside mountain tunnel portal: the first type is adopting a variety of sensor monitoring means on the ground, e.g., vertical slant monitoring hole [3], external vertical monitoring pier, vertical displacement monitoring, multipoint displacement meter, and GNSS, to monitor internal deformation, external deformation, and seepage pressure of cracking body and stress of supporting body, etc. $[4,5]$. These means have advantages of high precision and reliable results, and their disadvantages are spending too much manpower and material resources, high cost, sparse measuring points, long interval before repetition measuring, cannot effectively guaranteeing the safety of monitoring personnel, small monitoring scope, and severe environment influence [6]. Besides, most side slopes of highways locate in remote mountains and canyons, employees have large fluidity and uneven professional quality, and they are prone to have strong thinking inertia and fluky mind. Their safety awareness is weak, and then the accuracy and timeliness of monitoring data cannot be guaranteed due to measurement difficulty and serious influence of human factors [7]. The second type is adopting traditional surface deformation monitoring means such as GPS which have high precision, but they have low spatial density and cannot provide surface deformation information of the whole area $[8,9]$.

Differential interferometric synthetic aperture radar technique (INSAR technique) is a kind of space-to-earth observation technique [10]. In recent years, INSAR technique is in wide application stage of business, such as surface settlement observation and analysis of the southwest of Tianjin based on PS-INSAR technique, landslide seismic damage observation and analysis of Zhangmu Port of Tibet based on INSAR technique, geological disaster monitoring based on applying INSAR technique in Beidou satellite [11], and the application of INSAR technique in research of 
western coal mine goaf of Guizhou [12]. At present, INSAR technique has also made great progress in the field of surface deformation monitoring on highways. For example, PSINSAR technique was used to extract the settlement speed figure and settlement profile along Beijing-Shanghai highway and successfully identified 9 settlement centers along the highway [13]. And the section of Kunmo highway in Yunnan from Kunming to Yuxi was selected, and a "general survey" of disasters along the highway was conducted and then put forward suggestions for reasonable monitoring of the highway according to test results. However, the application of INSAR technique was still lacking in the field of tunnel and underground engineering construction. SBAS-INSAR technique was used to select scene 10 sentinel-1A data covering the engineering scope to conduct time sequence settlement monitoring on the tunnel engineering site [14], and settlement monitoring results of the engineering site was obtained. Then, the monitoring accuracy was evaluated and verified by actual leveling data [15]. Time sequence INSAR technique was adopted to monitor surface settlement along Beijing subway network. And taking Taoping tunnel of Houyue line as an example, INSAR technique was adopted for surface deformation monitoring investigation research of deep coal mine goaf in railway tunnel damage [16]. Above research studies primarily applied INSAR technique in the deformation monitoring of railway tunnel site [17], but as a millimeter level technique having higher reliability than traditional INSAR technique, PS-INSAR technique has not been applied in health diagnosis of the deformable body on front slope beside mountain tunnel portal [18, 19].

Based on the tunnel of Jianquan village, this paper uses PS-INSAR technique for the first time to analyze and diagnose the health condition of the deformable body on front slope beside mountain tunnel portal $[20,21]$. Through the inversion and long-term dynamic tracking of historical deformation of the deformable body on front slope beside tunnel portal, understanding and awareness of the slope deformation law in monitoring area are improved [22], thus providing a more scientific basis and reference for the early warning and treatment of the deformation of the deformable body on front slope beside tunnel portal.

\section{General Situation}

2.1. Characteristics of INSAR Technique. PS-INSAR technique is to use two synthetic aperture radar antennas with interference imaging ability (or use an antenna to repeat observation), to obtain two coherent single-view complex images from the same area with a certain angle of view [23], obtain surface elevation information by interference phase information, and then reconstruct the digital surface elevation model [24]. It is characterized by all-day and all-weather Earth observation without restrictions of light and climate conditions, and even the information covered by it can be obtained through the surface or vegetation [25]. The primary applications of this technique are to produce digital elevation models and to monitor the vertical direction of small displacements or deformations [26].
2.2. Basic Information of Front Slope beside the Portal of Jianquan Village Tunnel. The tunnel is located on the right bank of Hanyuan Lake in Hanyuan County, Ya'an. The highest elevation is over $1200 \mathrm{~m}$, the lowest elevation is about $800 \mathrm{~m}$ above the river bed of Dadu River, and the relative height difference is up to $400 \mathrm{~m}$. It belongs to Zhongshan landform. The tunnel is laid out in SE NW direction, the numbers of starting pile and ending pile are $\mathrm{K} 118+222 \sim \mathrm{K} 119+664$, and the length is $1442 \mathrm{~m}$.

The surrounding rock at the entrance of tunnel is primarily composed of colluvial deposits and silty mudstones, and the colluvial deposits are primarily composed of granular structure. The rock mass at the exit of tunnel is primarily silty mudstone, carbonaceous shale, and sandstone, which is soft rock and medium soft rock. The exit section $(\mathrm{K} 119+700)$ develops a toppling deformable body, and the surface occurrence of the deformable body is $143^{\circ} \angle 32^{\circ}$. Because of the steep dip angle of surface rock mass, it is pulled by gravity to topple outwards. The distribution elevation of the deformable body is $914 \sim 1050 \mathrm{~m}$, and the lowest point is $23 \mathrm{~m}$ away from the tunnel roof.

\section{The Application of PS-INSAR Technique in Diagnosing Deformable Body on Front Slope beside Tunnel Portal}

\subsection{Technical Parameter Selection}

3.1.1. SAR Data Selection. Sentinel-1 is a two-satellite Earth observation satellite operated by the European Space Agency's Copernicus Project (GMES) [27]. It consists of two satellites, c-band synthetic aperture radar (frequency: $5.4 \mathrm{GHz}$ ), with a 12-day revisit cycle. Sentinel-1 satellite SAR data is used to obtain the distribution map in the operation area (shown in Figure 1). Inside it, IW shooting mode can obtain SAR image data with a resolution of $5 \mathrm{~m} \times 20 \mathrm{~m}$ and a width of $250 \mathrm{~km}$. Here, scene 68 data from 2018 to 2020 were selected.

3.1.2. SAR Data Processing. Key steps of INSAR interferometric data processing process were (1) selection of public primary image, (2) image registration, (3) differential interference processing, (4) target extraction of point CS, (5) INSAR phase unwrapping, (6) linear deformation phase and residual elevation phase calculation, and (7) estimation and removal of error and atmospheric effect.

Among them, the basic principle of differential interference processing was that, after scene 68 image registration, all auxiliary images were resampled to primary images space. In frequency domain, public frequency band of primary and auxiliary images was prefiltered to generate the filtered primary and auxiliary images. After resampling, all auxiliary images were multiplied by the conjugate of the main image to generate interference phase diagram of images. Obtained phase information included the information of surface deformation, surface terrain phase, and so on. Meanwhile, the data of external digital elevation model (DEM) was used to simulate terrain phase, and the terrain phase of interference graph generated in this step was 


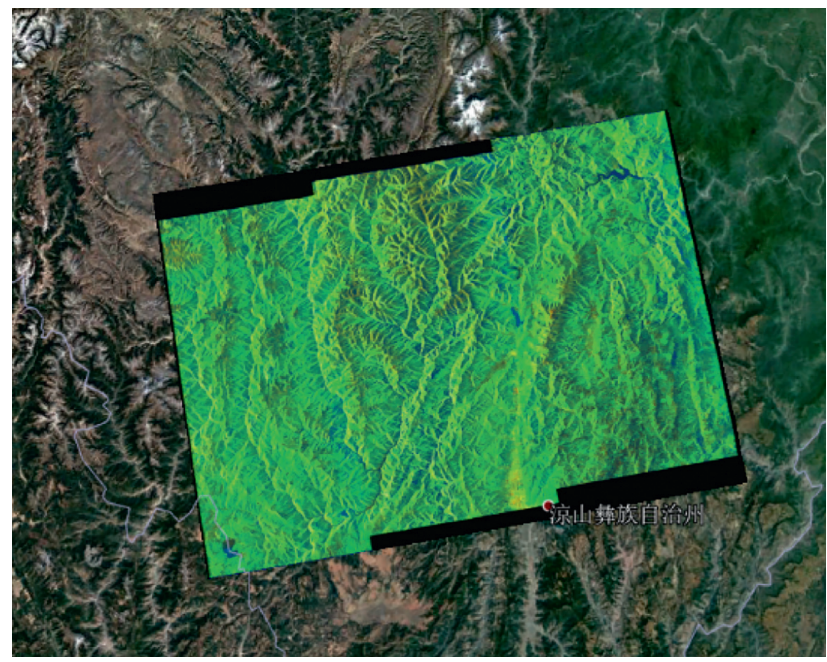

FIgURE 1: Distribution of SAR data operation area.

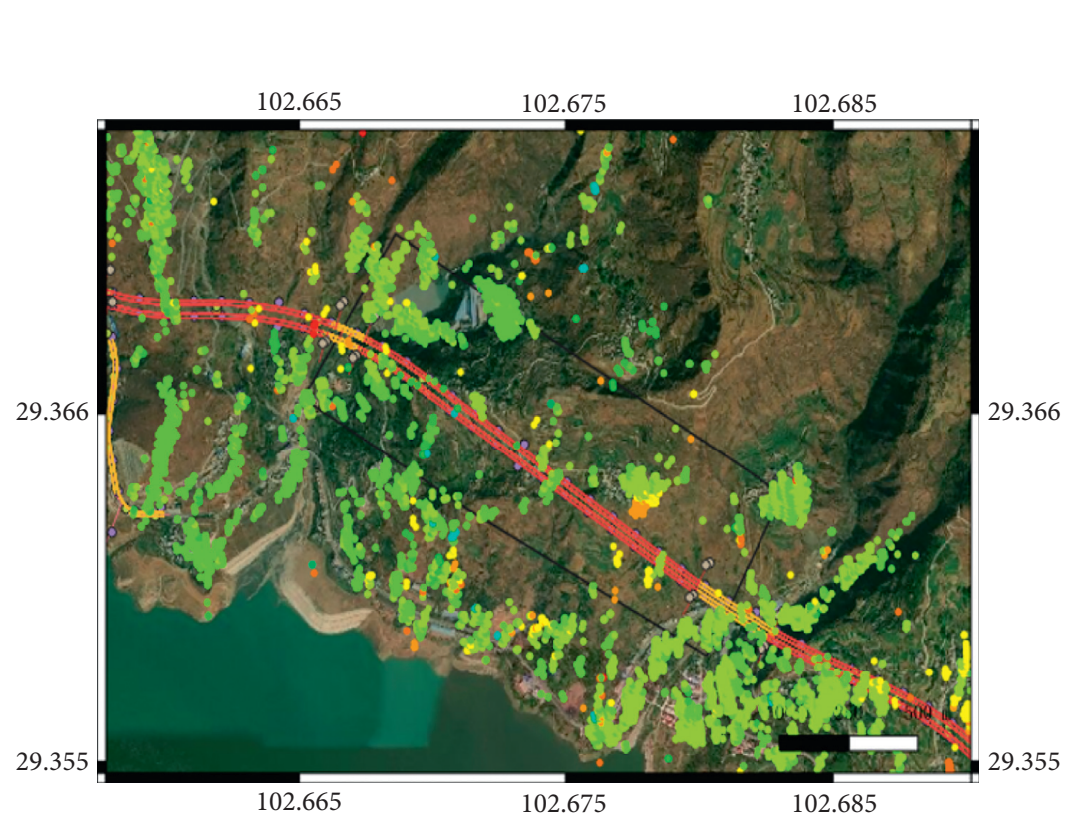

\begin{tabular}{c|c|}
\multicolumn{2}{c}{ Hanyuan, Sichuan } \\
TSInSAR \\
\begin{tabular}{|c|c|}
\hline Satellite & Santinel-1 \\
\hline $\begin{array}{c}\text { Imaging } \\
\text { method }\end{array}$ & Ascending \\
\hline Baseline & $200 \mathrm{~m}$ \\
\hline $\begin{array}{c}\text { Monitoring } \\
\text { period }\end{array}$ & 12 days \\
\hline Date & $2018 / 01-20202 / 04$ \\
\hline
\end{tabular}
\end{tabular}

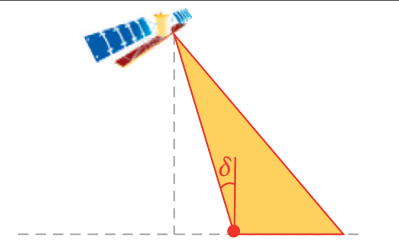

$\delta=39.085^{\circ}$

Deformation rate $(\mathrm{mm} / \mathrm{year})$

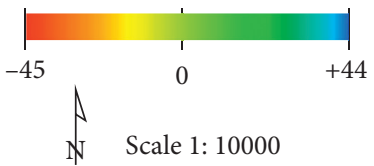

Coordinate system: WGS-84

Figure 2: Distribution of deformation speeds of front slope beside tunnel portal.

removed to generate differential interference graph. At this point, the phase of the X-th scatterer point (PS) of the $i$ th differential interference graph was obtained as follows:

$$
\phi_{x, i}=\phi_{D, x, i}+\phi_{A, x, i}+\phi_{S, x, i}+\phi_{\theta, x, i}+\phi_{N, x, i}
$$

where $\phi_{D, x, i}$ is the deformation phase in view direction; $\phi_{A, x, i}$ is the atmospheric influence phase; $\phi_{S, x, i}$ is the orbit error phase; $\phi_{\theta, x, i}$ is the residual terrain phase due to DEM error; and $\phi_{N, x, i}$ is the noise phase.

\subsection{Deformation Monitoring Calculation Results}

3.2.1. Deformation Monitoring Calculation Results of Front Slope beside Tunnel Portal. Deformation speeds distribution in the whole research area is shown in Figure 2. 70\% of them were between -10 and $+10 \mathrm{~mm} /$ year. Overall, the deformation speeds ranged from -26.277 to $+15.42 \mathrm{~mm} /$ year.

3.2.2. Deformation Monitoring Calculation Results of the Entrance Section of Jianquan Village Tunnel. According to deformation monitoring results of the entrance section of Jianquan village tunnel shown in Figure 3, the location was $29.3603388^{\circ} \mathrm{N}$ and $102.67806388^{\circ} \mathrm{E}$. The deformation value of point TS1 continued to decrease from October 2018 to October 2019 and is relatively stable recently. Its accumulative settlement maximum in two years was about $30 \mathrm{~mm}$, and the annual settlement speed was $12.628 \mathrm{~mm}$ /year. Point TS2 continued to settle from April 2018 to April 2020 


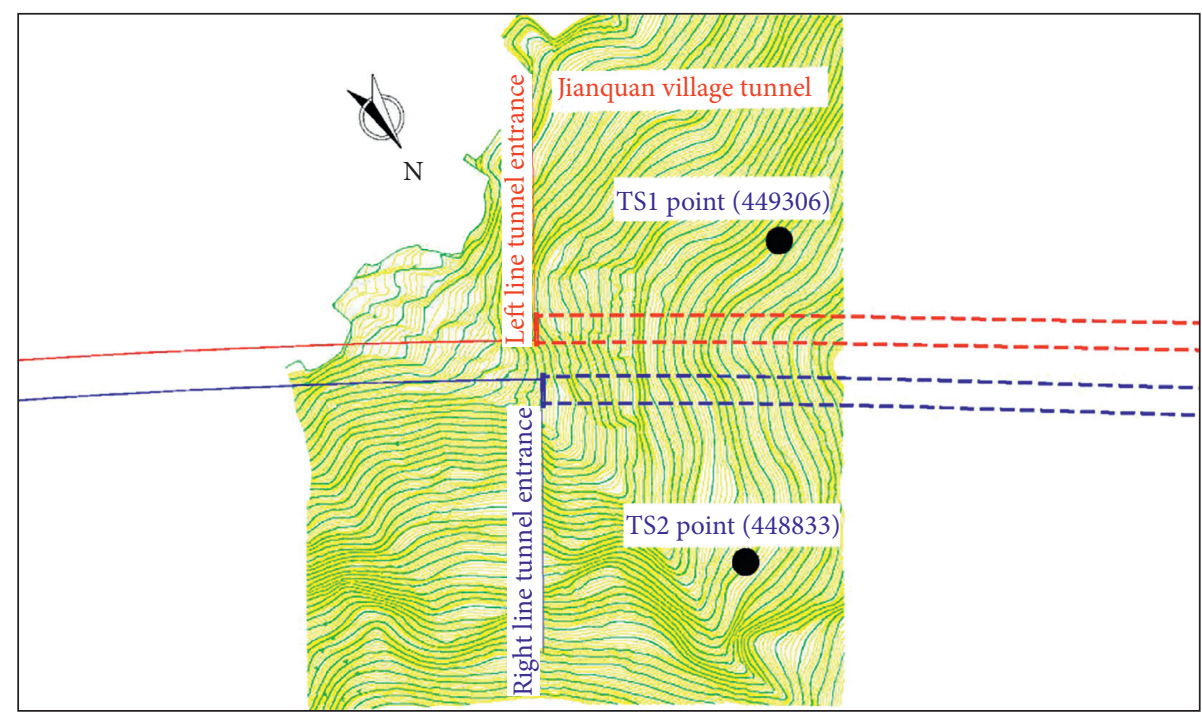

FIGURE 3: Deformation monitoring results of the entrance section of Jianquan village tunnel.

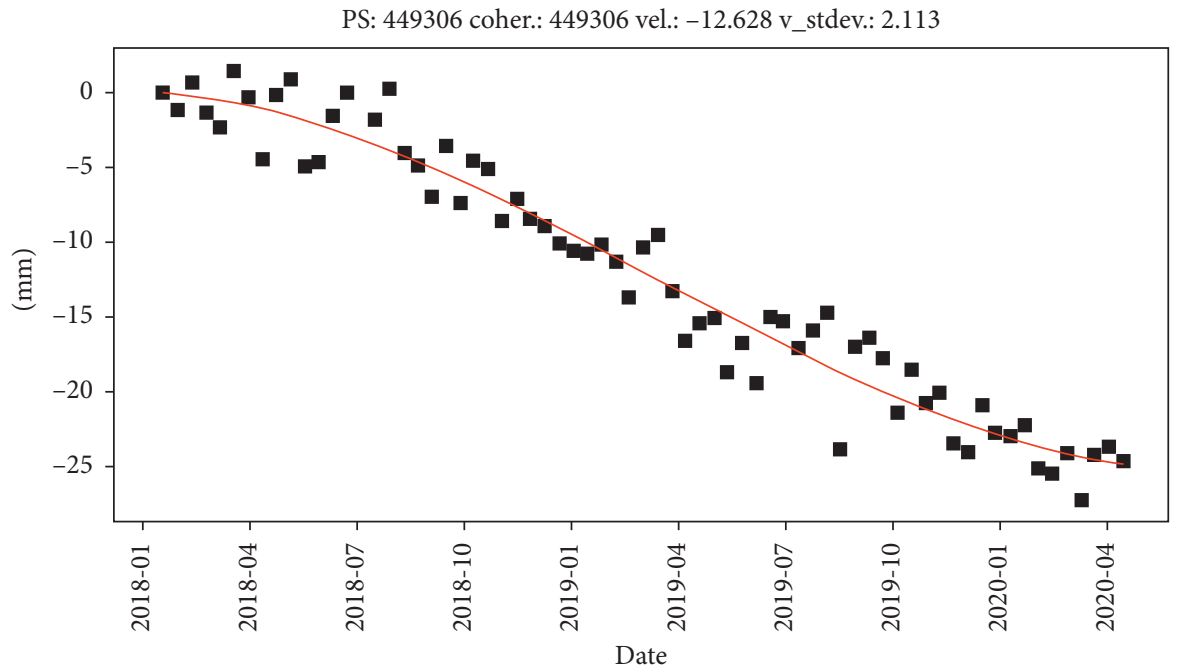

(a)

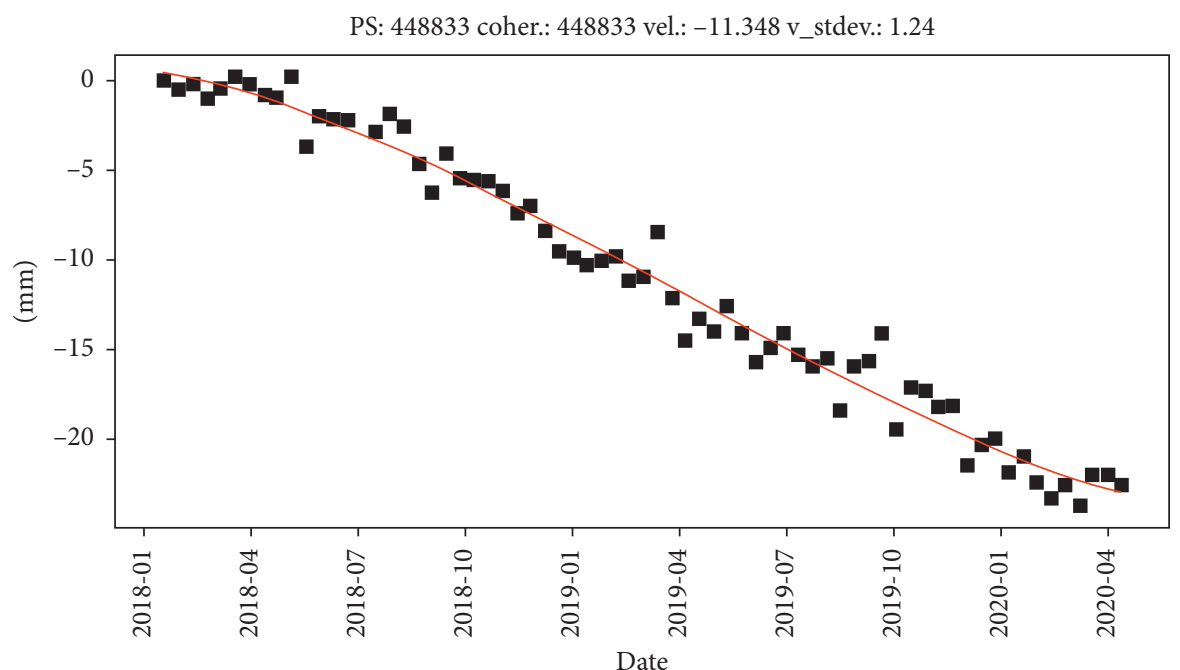

(b)

FIGURE 4: Time sequence deformation curves: (a) TS1 point (449306) and (b) TS2 point (448833). 


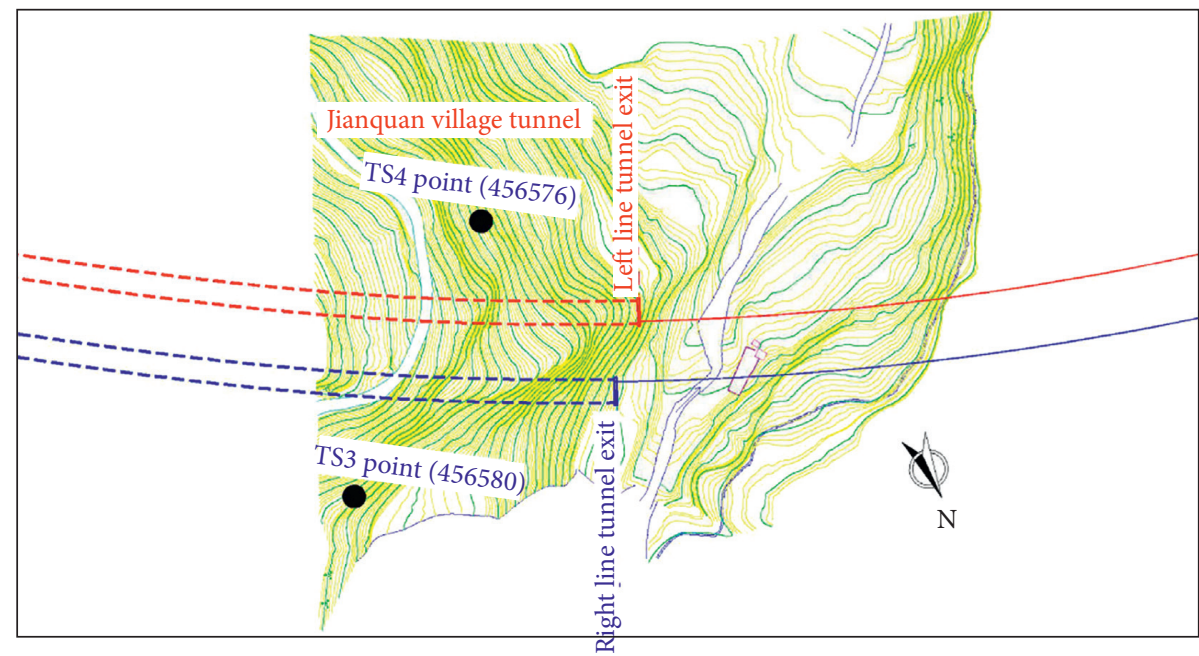

FIGURE 5: Deformation monitoring results of the exit section of Jianquan village tunnel.

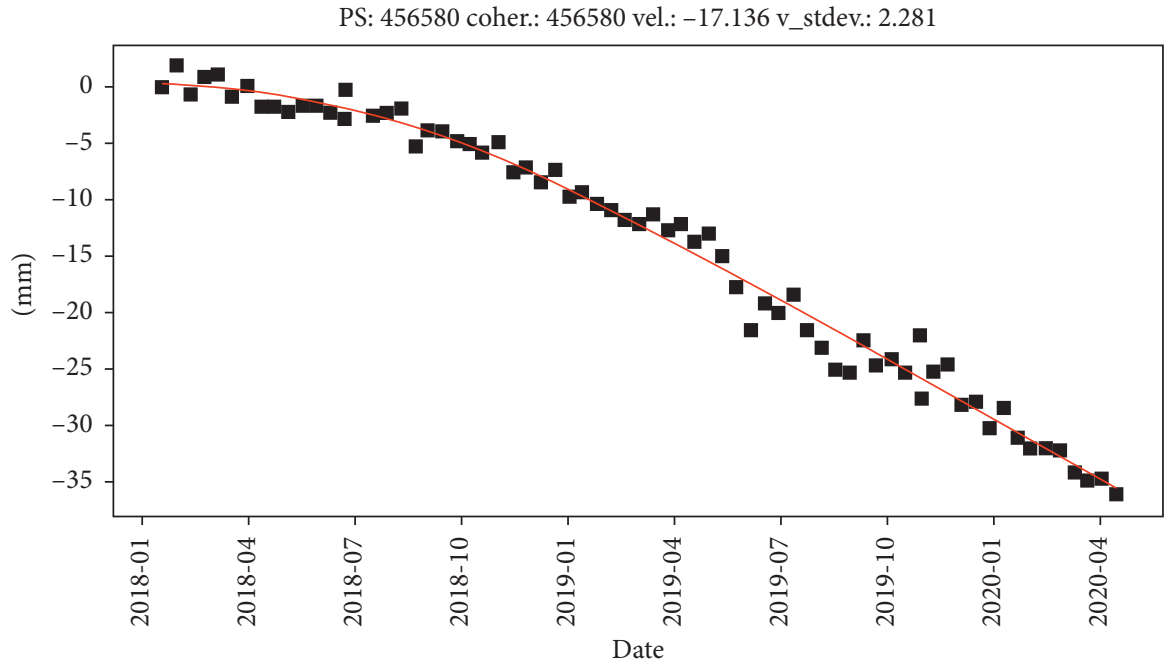

(a)

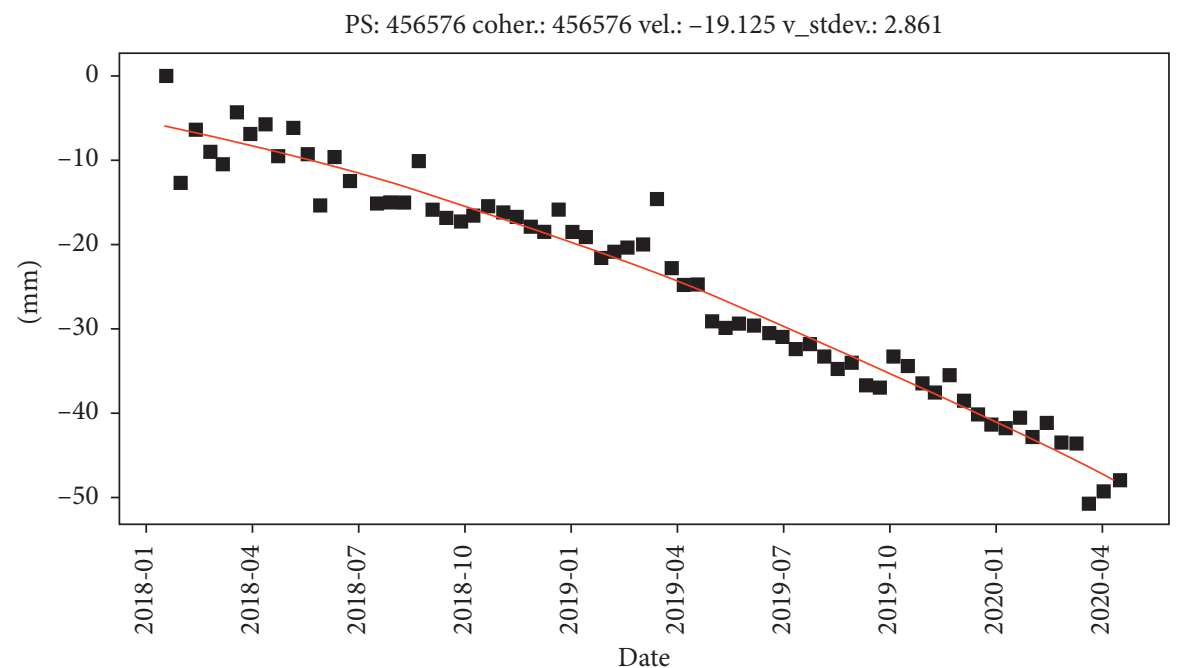

(b)

Figure 6: Time sequence deformation curves: (a) TS3 point (456580) and (b) TS4 point (456576). 
(Figure 4). The cumulative settlement maximum in two years was about $25 \mathrm{~mm}$, and the annual settlement speed was $11.348 \mathrm{~mm} /$ year.

\subsubsection{Deformation Monitoring Calculation Results of the Exit} Section of Jianquan Village Tunnel. According to deformation monitoring results of the exit section of Jianquan village tunnel shown in Figure 5, the location was $29.362805^{\circ} \mathrm{N}$ and $102.677111^{\circ} \mathrm{E}$. The deformation values continued to decrease from October 2018 to April 2020. The cumulative settlement maximum of point TS3 in two years was more than $35 \mathrm{~mm}$, and the annual settlement speed was $17.136 \mathrm{~mm} /$ year. The cumulative settlement maximum of point TS4 in two years was about $50 \mathrm{~mm}$, and the annual settlement speed was $19.125 \mathrm{~mm} /$ year.

3.3. Analysis of Deformation Monitoring Results. By using PS-INSAR technique to conduct quantitative analysis on the surface deformation of front slope beside Jianquan village tunnel portal in Emeishan-Hanyuan highway, the following results are obtained: through precise analysis on the surface deformation speed of Jianquan village tunnel in Emeishan-Hanyuan highway from January 2018 to April 2020, as exhibited in Figure 6, it is found that the exit section $(\mathrm{K} 119+700)$ of Jianquan village develops a deformable body, which is consistent with original investigation results. The annual deformation speed maximum of this deformable body is $19.125 \mathrm{~mm} /$ year, the annual deformation speed of section K118+400 is $11.348 \mathrm{~mm} /$ year, and this quantitative analysis of the change of the deformable body has important value to guide the treatment of the deformable body on front slope beside tunnel portal.

\section{Conclusions}

By using PS-INSAR technique to conduct research and analysis on the surface deformation law of front slope beside tunnel portal, the development state of the deformable body is quantitatively grasped, and the parameters (position, deformation speed, accumulative deformation, etc.) of the deformable body on front slope beside tunnel portal are obtained. Therefore, health condition of the bad deformable body is diagnosed. Then, the "bull's-eye" advantage is taken to detect early and treat early, which can attain the effect of rapid warning and precise management, reduce the safety risk during periods of tunnel construction and operation, and reduce deformation treatment cost.

\section{Data Availability}

The data are mainly composed of graphs and tables in the paper and can be referenced.

\section{Conflicts of Interest}

The author declares no conflicts of interest.

\section{Acknowledgments}

This research was supported by the Miaozi Engineering Key Project of the Science and Technology Department of Sichuan Province (grant no. 2020JDRC0078) and the State Key Laboratory of Geohazard Prevention and Geoenvironment Protection (China) Open Fund (grant no. SKLGP2020K018).

\section{References}

[1] W.-F. Chen, H.-L. Gong, B.-B. Chen, K.-S. Liu, M. Gao, and C.-F. Zhou, "Spatiotemporal evolution of land subsidence around a subway using InSAR time-series and the entropy method," GIScience \& Remote Sensing, vol. 54, no. 1, pp. 78-94, 2016.

[2] B. Bayer, A. Simoni, D. Schmidt, and L. Bertello, "Using advanced InSAR techniques to monitor landslide deformations induced by tunneling in the Northern Apennines, Italy," Engineering Geology, vol. 226, pp. 20-32, 2017.

[3] K. Teshebaeva, H. Echtler, and B. Bookhagen, "Deep-seated gravitational slope deformation (DSGSD) and slow-moving landslides in the southern Tien Shan Mountains: new insights from InSAR, tectonic and geomorphic analysis," Earth Surface Processes and Landforms, vol. 44, no. 12, pp. 2333-2348, 2019.

[4] J. Scoular, R. Ghail, P. Mason et al., "Retrospective InSAR analysis of east london during the construction of the lee tunnel," Remote Sensing, vol. 12, p. 5, 2020.

[5] Y. Chen, K. Tan, S. Y. Yan et al., "Monitoring land surface displacement over Xuzhou (China) in 2015-2018 through PCA-based correction applied to SAR interferometry," Remote Sensing, vol. 11, p. 12, 2019.

[6] C. Noviello, S. Verde, V. Zamparelli et al., "Buildings at landslide risk with SAR: a methodology based on the use of multipass interferometric data," IEEE Geoscience and Remote Sensing Magazine, vol. 8, no. 1, pp. 91-119, 2019.

[7] J. Zhou, P. Ezquerro, J. A. Fernández-Merodo et al., "Analysis of an open-pit slope failure: las cruces case study, Spain," Landslides, vol. 17, no. 9, pp. 2173-2188, 2020.

[8] Ł. Rudziński, K. Mirek, and J. Mirek, "Rapid ground deformation corresponding to a mining-induced seismic event followed by a massive collapse," Natural Hazards, vol. 96, no. 1, pp. 461-471, 2018.

[9] A. J. García, M. Marchamalo, R. Martínez, B. GonzálezRodrigo, and C. González, "Integrating geotechnical and SAR data for the monitoring of underground works in the Madrid urban area: application of the persistent scatterer interferometry technique," International Journal of Applied Earth Observation and Geoinformation, vol. 74, pp. 27-36, 2018.

[10] M. González, I. Armaş, P. Dumitru, and M. Necsoiu, "Subway construction using Sentinel-1 data: a case study in Bucharest, Romania," International Journal of Remote Sensing, vol. 41, no. 7, pp. 2644-2663, 2019.

[11] R. Guo, S. M. Li, Y. N. Chen, X. Li, and L. Yuan, "Identification and monitoring landslides in longitudinal range-gorge region with InSAR fusion integrated visibility analysis," Landslides, vol. 15, 2020.

[12] G. Giardina, P. Milillo, M. J. DeJong et al., "Evaluation of InSAR monitoring data for post-tunnelling settlement damage assessment," Structural Control and Health Monitoring, vol. 26, no. 2, Article ID e2285, 2018.

[13] X. G. Shi, Q. Xu, and L. Zhang, "Surface displacements of the heifangtai terrace in Northwest China measured by $\mathrm{X}$ and 
C-band InSAR observations," Engineering Geology, vol. 259, 2019.

[14] P. Milillo, G. Giardina, and M. DeJong, "Multi-temporal InSAR structural damage assessment: the london crossrail case study," Remote Sensing, vol. 10, p. 2, 2018.

[15] X. Hu, R. Burgmann, W. H. Schulz, and F. J. Fielding, "Fourdimensional surface motions of the Slumgullion landslide and quantification of hydrometeorological forcing," Nature Communications, vol. 11, no. 1, p. 2792, 2020.

[16] L. Zhou, J. Guo, J. Hu, J. Maau, F. Weiau, and X. Xue, "Analysis of ELH Bridge through ground-based interferometric radar during the crossing of a subway shield tunnel underneath the bridge," International Journal of Remote Sensing, vol. 39, no. 6, pp. 1911-1928, 2017.

[17] M. Pauciullo, D. Piacentini, and E. Tirincanti, "Detection and monitoring of tunneling induced ground movements using sentinel-1 SAR interferometry," Remote Sensing, vol. 11, p. 6, 2019.

[18] A. A. Malinowska, W. T. Witkowski, and R. Hejmanowski, "Sinkhole occurrence monitoring over shallow abandoned coal mines with satellite-based persistent scatterer interferometry," Engineering Geology, vol. 262, 2019.

[19] G. Strecker, M. Komac, and M. Jemec, "PS-InSAR displacements related to soil creep and rainfall intensities in the Alpine foreland of western Slovenia," Geomorphology, vol. 175, p. 176, 2012.

[20] C. Crippa, F. Franzosi, M. Zonca et al., "Unraveling spatial and temporal heterogeneities of very slow rock-slope deformations with targeted DInSAR analyses," Remote Sensing, vol. 12, p. 8, 2020.

[21] M. Khorrami, B. Alizadeh, and T. E. Ghasemi, "How groundwater level fluctuations and geotechnical properties lead to asymmetric subsidence: a PSInSAR analysis of land deformation over a transit corridor in the los angeles metropolitan area," Remote Sensing, vol. 11, p. 4, 2019.

[22] B. W. Lowry, S. Baker, and W. Zhou, "A case study of novel landslide activity recognition using ALOS-1 InSAR within the ragged mountain western hillslope in gunnison county, Colorado, USA," Remote Sensing, vol. 12, p. 12, 2020.

[23] X. T. Chen, X. F. He, and X. L. Yang, "Terrain point cloud assisted GB-InSAR slope and pavement deformation differentiate method in an open-pit mine," Sensors (Basel).vol. 20, p. 8,2020 .

[24] M. Bădescu, A. Gaber, F. Abdalla et al., "Use of optical and radar remote sensing satellites for identifying and monitoring active/inactive landforms in the driest desert in Saudi Arabia," Geomorphology, vol. 362, 2020.

[25] D. Marsh, G. Wang, T. Yang, and F. Zhang, "Remote sensingbased detection of the deformation of a reservoir bank slope in Laxiwa hydropower station, China," Landslides, vol. 10, no. 2, pp. 231-238, 2015.

[26] A. Hu, M. T. Hendry, and R. Macciotta, "GB-InSAR monitoring of vegetated and snow-covered slopes in remote mountainous environments," Landslides, vol. 17, no. 7, pp. 1713-1726, 2017.

[27] Y. Tian, J. Liu-Zeng, Y. Luo et al., "Deformation during the Milashan Tunnel construction in northern sangri-cuona rift, Southern Tibet, China observed by Sentinel-1 satellites," Science Bulletin, vol. 63, no. 21, pp. 1439-1447, 2018. 